\title{
Release of Anticancer Drug 5-Fluorouracil from Different Ionically Crosslinked Alginate Beads
}

\author{
Merve Olukman $^{1}$, Oya Şanlı ${ }^{*}$, Ebru Kondolot Solak ${ }^{2}$ \\ ${ }^{1}$ Department of Chemistry, Faculty of Science, Gazi University, Ankara, Turkey; ${ }^{2}$ Department of Chemistry and Chemical Process- \\ ing Technology, Atatürk Vocational High School, Gazi University, Ankara, Turkey. \\ Email: 'osanli@gazi.edu.tr
}

Received June $5^{\text {th }}, 2012$; revised July $11^{\text {th }}, 2012$; accepted August $19^{\text {th }}, 2012$

\begin{abstract}
In this research, the release of 5-Fluorouracil (5-FU) from different ionically crosslinked alginate (Alg) beads was investigated by using $\mathrm{Fe}^{3+}, \mathrm{Al}^{3+}, \mathrm{Zn}^{2+}$ and $\mathrm{Ca}^{2+}$ ions as crosslinking agent. The prepared beads were characterized by Fourier Transform Infrared Spectroscopy (FTIR) Differential Scanning Calorimetry (DSC) and Scanning Electron Microscopy (SEM). The drug release studies were carried out at three $\mathrm{pH}$ values 1.2, 6.8 and 7.4 respectively each for two hours. The effects of the preparation conditions as crosslinker type, drug/polymer (w/w) ratio, crosslinker concentration and time of exposure to crosslinker on the release of 5-FU were investigated for 6 hours at $37^{\circ} \mathrm{C}$. It was observed that 5-FU release from the beads followed the order of $\mathrm{Fe}>\mathrm{Zn}>\mathrm{Al}>\mathrm{Ca}-\mathrm{Alg}$ and increased with increasing drug/polymer ratio. At the end of 6 hours, the highest 5-FU release was found to be $90 \%(\mathrm{w} / \mathrm{w})$ for Fe-Alg beads at the drug/polymer ratio of $1 / 8(\mathrm{w} / \mathrm{w})$, crosslinker concentration of $0.05 \mathrm{M}$, exposure time of 10 minutes respectively. The swelling measurements of the beads supported the release results. Release kinetics was described by Fickian and non-Fickian approaches.
\end{abstract}

Keywords: Anticancer Drug; pH Responsive Release; Alginate; Ionically Crosslinking; Controlled Release; 5-Fluorouracil

\section{Introduction}

5-Fluorouracil (5-FU) is one of the most widely used agents in cancer theraphy. Since its active form inhibits DNA synthesis by inhibiting the normal production of thymidine. It has a relatively high response in colon, rectal, breast, gastrointestinal tract pancreas, head, ovarion cancers [1-4]. The common method of administration of 5 -FU is in the form of injections into vein $[1,5,6]$ (intravenous) or as an infusion. However, such an administration causes severe gastrointestinal (vomiting, nausea, poor appetite) neural, hematological, cardiac, dermatological toxic effects. Since the drug is rapidly adsorbed through blood capillaries into systematic circulation, results in relatively low levels of the drug near the side action with subsequent loss of efficiency and increased risk of toxicity. By using oral rate controlled formulations, the incidence of side effects may be reduced since the drug has short biological half-life due to fast metabolism incomplete and non uniform oral absorption [6]. There are many studies in the literature for encapsulation of 5-FU in polymeric materials. In those studies $[1,2,4$, 6-13]. Generally natural polymers were preffered to syn-

*Corresponding author. thetic polymers for the encapsulation because of their free aviability, nontoxicity and biodegrability characteristics. These polymers eventually undergo hydrolytic scission, producing by products that can be metabolized in the body. Polymers like gelation [14]. Chi-tosan [15], copoly(D,L-lactic/glycolic acid [16], poly(D-L-Lactide-coglycolide) [1] have been used in the controlled delivery of 5-FU.

There are also some studies concerning the encapsulation of 5-FU into alginate matrix $[12,17,18]$ but they are in a limited number. Alginate is a lineer copolymer of D-Mannuric acid (M) and Gluronic acid (G) units which is found in brown seaweeds and is commercially available as sodium salt. It is a cellulose based biodegredable type polymer and is widely used in pharmaceutical applicatinos [18-29]. Gel formation of alginate matrix is generally achieved by using divalent $\mathrm{Ca}^{2+}$ ions $[19,21,22$, 24-29]. However calcium-alginate beads or microparticles when exposed to highly acidic (pH: 1.2) environment of stomach may result in insoluble alginic acid form causing reduction in their degree of crosslinking hence the beads degrades in a very short time after arriving to colon (pH: 6.8, 7.4). For this reason Arica et al. [27] and Sure- 
kha et al. [28] studied the release of 5-FU only at $\mathrm{pH}$ conditions of 7.4, Chui-Yu et al. Reinforced alginate microparticles by chitosan during gelation [13]. Dodova et al. [12] prepared lectin-conjugated chitosan-Caalginate microparticles and loaded with 5-FU for the same purpose.

In the present study we have aimed to increase the strength of alginate beads so that after passing through stomach they can stand for a longer time period in intestinal medium conditions. For this reason we have tried different metal ions as $\mathrm{Fe}^{3+}, \mathrm{Al}^{3+}, \mathrm{Zn}^{2+}, \mathrm{Ca}^{2+}$ for the crosslinking of alginate matrix, tried to find most suitable cation for the crosslinking and evaluated the physicochemical properties of the beads prepared. Attention has been paid for the effects of various factors on the release such as drug/polymer ratio, $\mathrm{pH}$ of the dissolution medium, crosslinking time and concentration. Although $\mathrm{Fe}^{3+}$ ions were previously used for the preparation of crosslinked alginate-carboxymethyl cellulose beads for protein theraupeutics [30] and carboxymethyl chitin nanoparticles for 5-FU delivery [31]. There is no study concerning the use of these ions in the delivery of 5-FU from the alginate matrix.

\section{Experimental}

\subsection{Materials}

$\mathrm{NaAlg}$ (medium viscosity) was purchased from Sigma Chemical Co (Louis, USA). 5-FU was provided by SigmaAldrich (Steinem, Germany). $\mathrm{Na}_{2} \mathrm{HPO}_{4}$ and $\mathrm{NaH}_{2} \mathrm{PO}_{4}$ were all supplied from Merck (Darmstadt, Germany) and were used as received. Iron (III) chloride, Aluminum chloride, zinc chloride and calcium chloride were provided by Merck (Darmstadt, Germany).

\subsection{Preparation of the 5-FU Loaded Beads}

$\mathrm{NaAlg}$ was dissolved in distilled water to prepare $2 \%$ (w/v) NaAlg solution. Different amounts of 5-FU were added and mixed using a magnetic stirrer. The polymer solution containing 5-FU was added drop wise into crosslinking solution using a peristaltic pump (Masterflex, L/S Digital Economy Drive, USA). The formed beads were then removed from the crosslinker solution. To remove the adhered crosslinker, beads were washed with water repeatedly then dried completely in an oven at $40^{\circ} \mathrm{C}$. Preparation conditions were displayed in Table 1. In order to estimate the size of beads completely dry beads from the different formulations were selected and their sizes were measured by using a micrometer screw gauge (Aldrich, Germany) and given in Table 1.

\subsection{Equilibrium Swelling Study of the Beads}

Equilibrium swelling degree of the crosslinked empty beads was determined by measuring gravimetrically the extent of their swelling in solutions at $\mathrm{pH} 1.2,6.8$ and 7.4 at $37^{\circ} \mathrm{C}$. To ensure complete equilibration, the samples were allowed to swell for $24 \mathrm{~h}$. The excess surface-adhered liquid drops were removed by blotting. The swollen beads were weighed using electronic balance (Precise XB 220 A, USA). The beads were then dried in an oven at $40^{\circ} \mathrm{C}$, until there was no change in the dried mass of the samples. The percent equilibrium swelling degree was calculated as follows:

Equilibrium swelling degree (\%) $=\frac{M_{s}-M_{d}}{M_{d}} \times 100$

where $M_{s}$ and $M_{d}$ were the mass of the swollen beads and dry beads, respectively.

Table 1. Preparation conditions of the 5-Fluorouracil loaded NaAlg beads.

\begin{tabular}{|c|c|c|c|c|c|c|c|}
\hline Code & $\begin{array}{l}\text { Drug/Polymer } \\
\text { ratio }(w / w)\end{array}$ & $\begin{array}{l}\text { Crosslinking } \\
\text { agent }\end{array}$ & $\begin{array}{l}\text { Concentration of } \\
\text { crosslinking agent }(\mathrm{M})\end{array}$ & $\begin{array}{c}\text { Exposure time to } \\
\text { crosslinking agent (min) }\end{array}$ & $\begin{array}{c}\text { Entrapment } \\
\text { efficiency (\%) }\end{array}$ & $\begin{array}{l}\text { Bead yield } \\
\quad(\%)\end{array}$ & $\begin{array}{l}\text { Bead diameter } \\
(\mathrm{mm})\end{array}$ \\
\hline A1 & $1 / 8$ & $\mathrm{FeCl}_{3}$ & 0.1 & 10 & 12 & 96 & 1.25 \\
\hline B1 & $1 / 8$ & $\mathrm{AlCl}_{3}$ & 0.1 & 10 & 5 & 93 & 1.17 \\
\hline $\mathrm{C} 1$ & $1 / 8$ & $\mathrm{CaCl}_{2}$ & 0.1 & 10 & 4 & 84 & 1.11 \\
\hline D1 & $1 / 8$ & $\mathrm{ZnCl}_{2}$ & 0.1 & 10 & 7 & 89 & 1.13 \\
\hline A2 & $1 / 8$ & $\mathrm{FeCl}_{3}$ & 0.2 & 10 & 15 & 75 & 0.62 \\
\hline A3 & $1 / 8$ & $\mathrm{FeCl}_{3}$ & 0.05 & 10 & 10 & 82 & 1.00 \\
\hline A4 & $1 / 8$ & $\mathrm{FeCl}_{3}$ & 0.05 & 5 & 17 & 70 & 0.55 \\
\hline A5 & $1 / 8$ & $\mathrm{FeCl}_{3}$ & 0.05 & 15 & 7 & 78 & 1.10 \\
\hline A6 & $1 / 4$ & $\mathrm{FeCl}_{3}$ & 0.05 & 10 & 13 & 77 & 1.06 \\
\hline A7 & $1 / 2$ & $\mathrm{FeCl}_{3}$ & 0.05 & 10 & 14 & 62 & 1.10 \\
\hline A8 & $1 / 1$ & $\mathrm{FeCl}_{3}$ & 0.05 & 10 & 25 & 50 & 1.20 \\
\hline
\end{tabular}




\subsection{Determination of 5-FU Content of the Beads}

The known mass of beads was crushed in an agate mortar with a pestle, and then polymeric powder is taken in a flask. Water $(50 \mathrm{~mL})$ was added and refluxed at $25^{\circ} \mathrm{C}$ for $1 \mathrm{~h}$, to ensure the complete extraction of 5-FU from the beads. At the end of the $1 \mathrm{~h}$, precipitated NaAlg was filtered and 5-FU was analyzed by using a UV spectrophotometer (Unico $4802 \mathrm{UV} / \mathrm{VIS}$ ) at a wavelength of 266 nm using a calibration curve and water as the blank. Percentage of entrapment efficiency was then calculated as follows:

$$
\begin{aligned}
& \text { Entrapment efficiency }(\%) \\
& =\frac{\text { Practical 5-FU loading }}{\text { Theoretical 5-FU loading }} \times 100
\end{aligned}
$$

\subsection{Fourier Transforms Infrared Measurements (FTIR)}

FTIR spectra of the 5-FU, NaAlg and 5-FU/NaAlg beads crosslinked with $\mathrm{Fe}^{3+}$ were taken with a Mattson 1000 FTIR spectrometer and presented in Figure 1.

\subsection{Differential Scanning Calorimetry (DSC)}

The thermal analysis was carried out with differential scanning calorimeter (DSC, Shimadzu, Japon). Measure ments were performed over the temperature range of $0^{\circ} \mathrm{C}$ $300^{\circ} \mathrm{C}$ at the heating rate of $10^{\circ} \mathrm{C} / \mathrm{min}$. and displayed Figure 2.

\subsection{Scanning Electron Microscopy (SEM)}

SEM micrographs were taken with QUANTA 400F Field

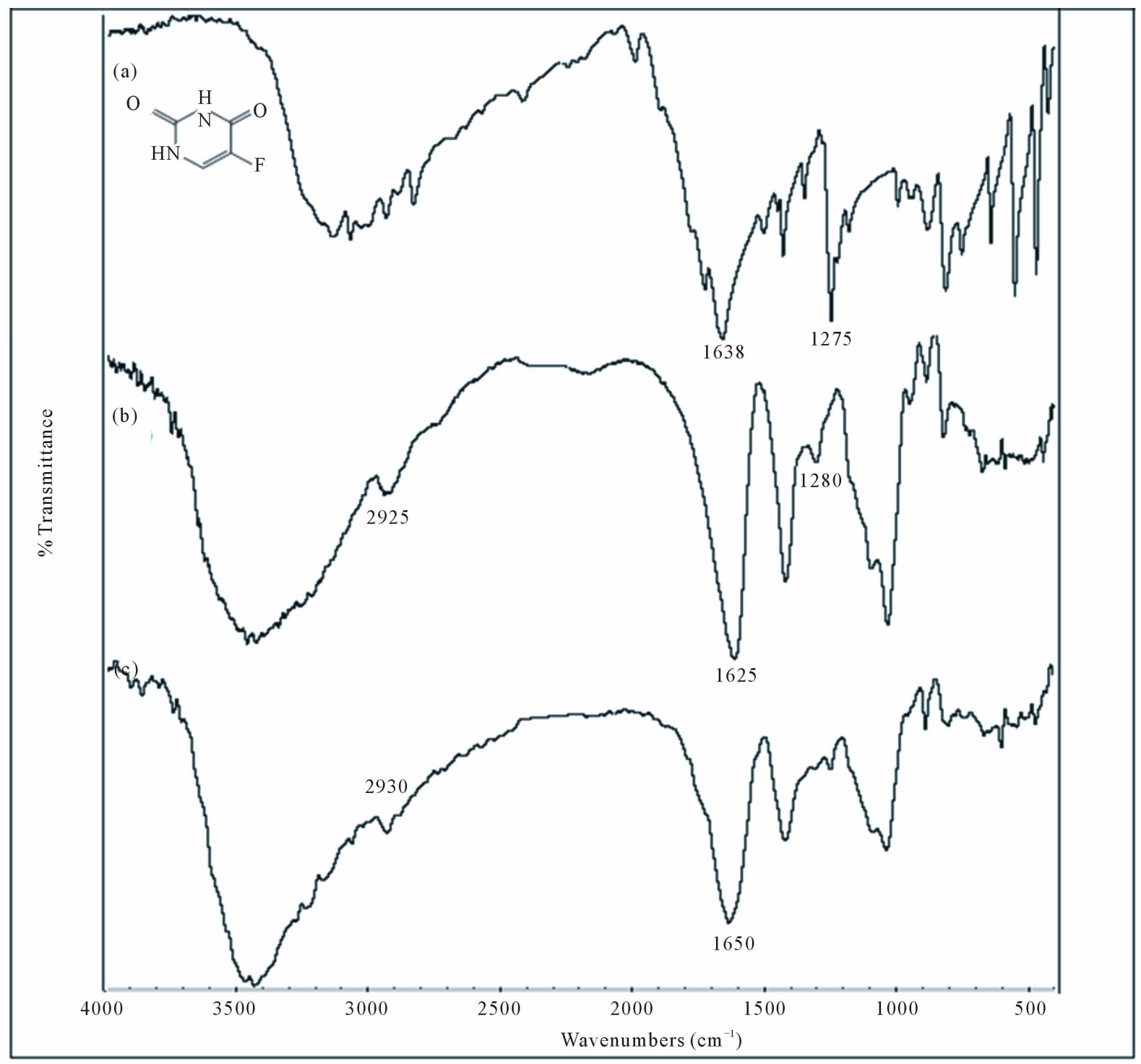

Figure 1. FTIR spectra of (a) 5-FU; (b) 5-FU loaded NaAlg (1/8 w/w) beads crosslinked with $\mathrm{Fe}^{3+}$; (c)NaAlg. 


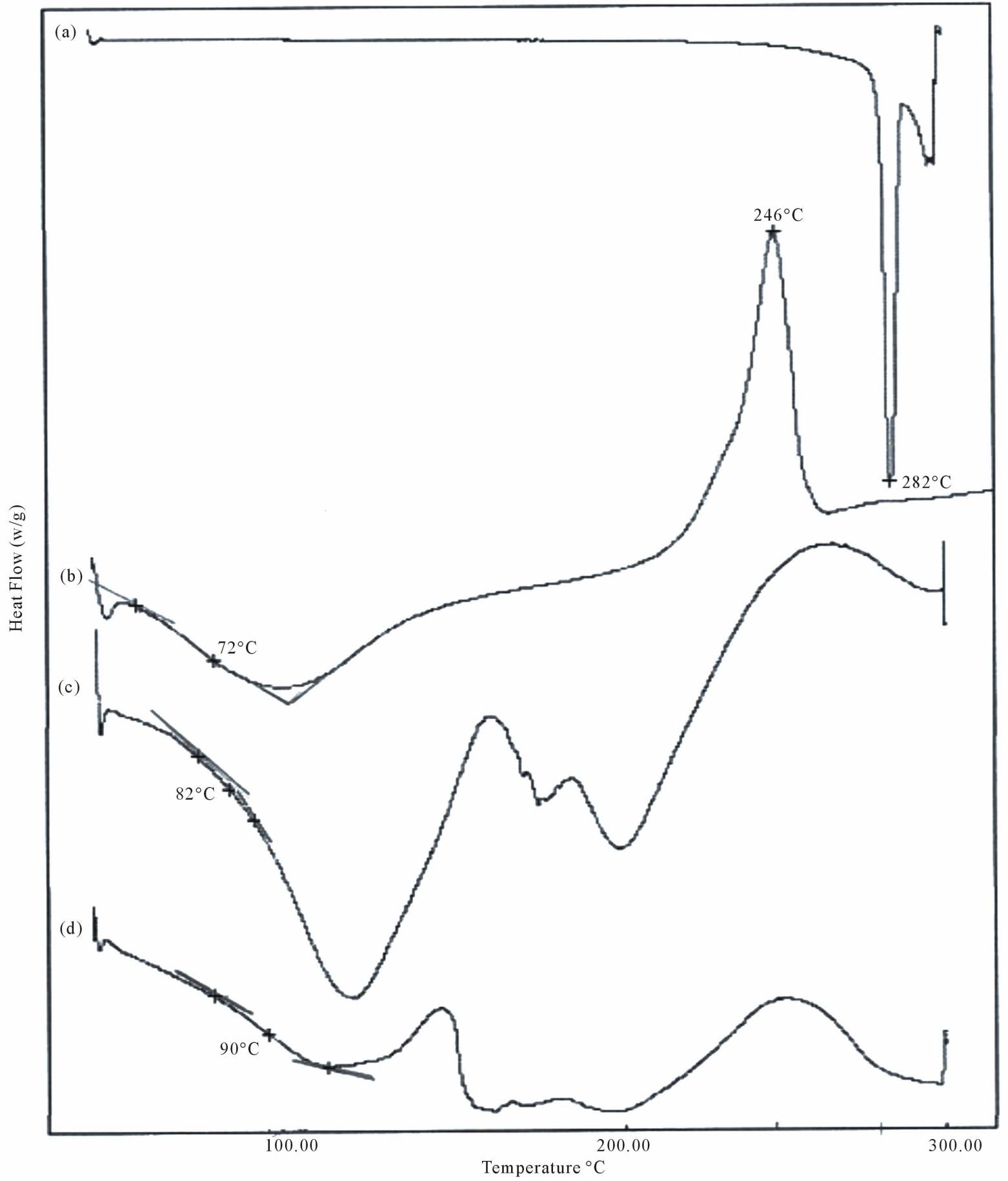

Figure 2. DSC termograms of (a) Pure 5-FU; (b) NaAlg; (c) NaAlg beads crosslinked with $\mathrm{FeCl}_{3}$; (d) 5-FU loaded beads crosslinked with $\mathrm{FeCl}_{3}$.

Emission SEM to examine the morphology and surface structure of the beads at the required magnification at room temperature and shown in Figure 3.

\subsection{In Vitro Drug Release}

In vitro drug release from the beads was studied in 250
mL, pH 1.2 HCl solution, $\mathrm{pH} 6.8$ and $\mathrm{pH} 7.4$ phosphate buffer solutions and incubated in a shaking water bath (Medline BS-21, Korea) at $37^{\circ} \mathrm{C}$. At $2 \mathrm{~h}$ intervals medium was changed to be $\mathrm{pH}: 1.2,6.8$ and 7.4 , respectively, to follow the gastrointestinal tract. At specific time intervals, the 5-FU content was determined using UV spectrophotometer at $266 \mathrm{~nm}$. Equal volume of fresh 
$\mathrm{HCl}$ or phosphate buffer solution was added into the dissolution media to maintain a constant volume. From the absorbance values the cumulative released amount percentage was determined. All experiments were performed in triplicate to minimize the variational error. Standard deviations from the average values were calculated.

\section{Results and Discussion}

\subsection{Effect of Type of Crosslinker and Crosslinker Concentration on the 5-FU Release}

The release of 5-FU from the Fe-Alg, Al-Alg, Ca-Alg and $\mathrm{Zn}$-Alg beads were carried out for three $\mathrm{pH}$ values at $37^{\circ} \mathrm{C}$ and the amount of drug release within a given time was evaluated by UV spectroscopy. Effect of type and valency of the ions in the crosslinking agents on the cumulative release of 5-FU were shown in Figure 4. It was reflected from the figure that cumulative drug release from beads followed the order of $\mathrm{Fe}>\mathrm{Zn}>\mathrm{Al}>\mathrm{Ca}-\mathrm{Alg}$ and the beads of $\mathrm{Zn}-\mathrm{Alg}$, Ca-Alg, Al-Alg eroded at the $\mathrm{pH}$ values higher than 6.8 (Table 2).

The release results can be related to the mechanism of the bonding of iron, aluminum, zinc and calcium ions with NaAlg. Since calcium and zinc cations are divalent, their bonding to alginate was expected to occur in a planar two-dimensional manner as represented in the egg-box model [32] shown in Scheme 1. Trivalent aluminium and iron cations were expected to form a three dimensional valent bonding structure with the alginate. Possible scheme for the crosslinking of NaAlg with $\mathrm{Fe}^{3+}$ and $\mathrm{Al}^{3+}$ was given in Scheme 2. Reaction mechanism of sodium alginate with $\mathrm{Zn}^{2+}$ and $\mathrm{Ca}^{2+}$ ions is similar to $\mathrm{Fe}^{3+}$ and $\mathrm{Al}^{3+}$. Dissimilarly two alginate chains were used in the crosslinking with $\mathrm{Zn}^{2+}$ and $\mathrm{Ca}^{2+}$.

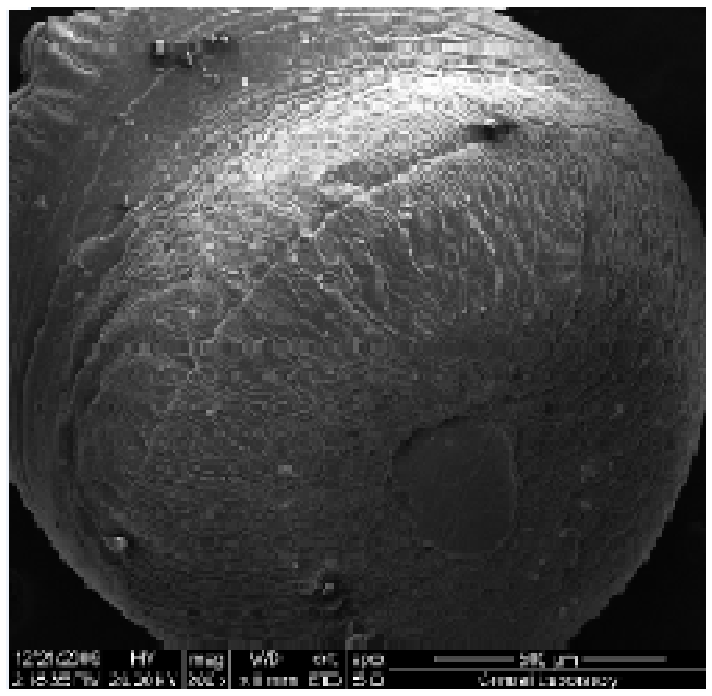

Figure 3. Microscopic pictures of (a) Empty Fe-Alg and (b) 5-FU loaded Fe-Alg beads.

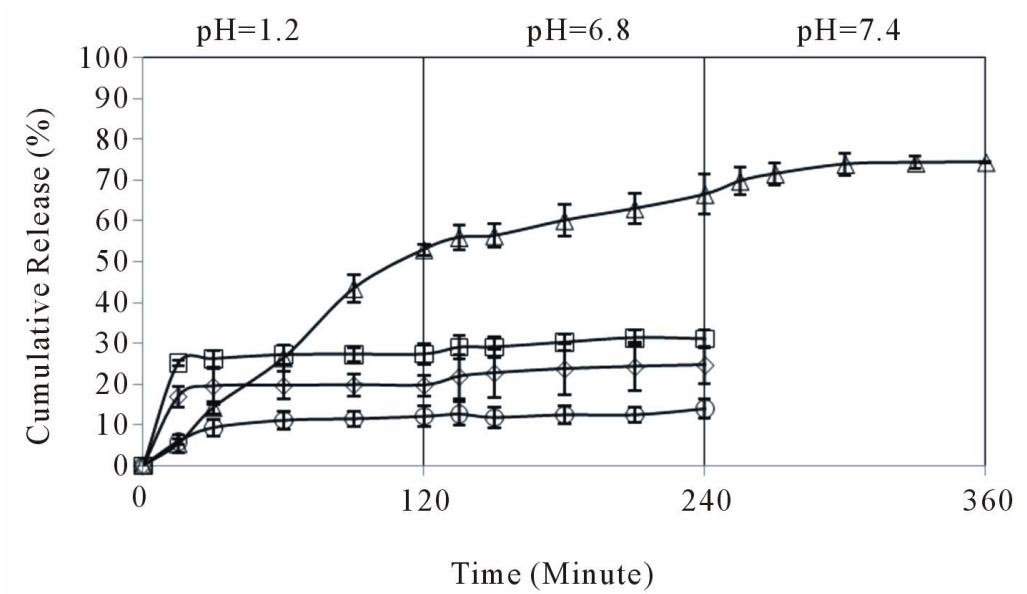

Figure 4. Effect of type and valency of the ions in the crosslinking agents on the cumulative release of 5-FU $\left(\Delta: \mathrm{FeCl} \mathrm{l}_{3}, \square\right.$ : $\left.\mathrm{ZnCl}_{2}, \diamond: \mathbf{A l C l}_{3}, \circ: \mathbf{C a C l}_{2}\right)$. 
Table 2. Equilibrium swelling degree for empty beads.

\begin{tabular}{cccc}
\hline Formulation Code & $\mathrm{pH}=1.2$ & $\mathrm{pH}=6.8$ & $\mathrm{pH}=7.4$ \\
\hline A & $51.19 \pm 1.07$ & $108.17 \pm 1.58$ & $188.65 \pm 2.46$ \\
B & $217.65 \pm 2.56$ & Beads eroded & Beads eroded \\
C & $135.58 \pm 1.44$ & Beads eroded & Beads eroded \\
D & $229.23 \pm 1.73$ & Beads eroded & Beads eroded
\end{tabular}

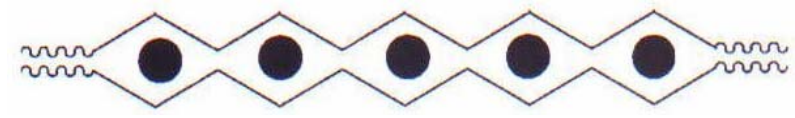

Scheme 1. Egg-box model representing $\mathrm{M}^{2+}$ cations reacting with alginates.

Three dimensional bonding model was expected to be the reason for the extended crosslinking through the whole body of matrix. On the other hand diffusion ability of the NaAlg crosslinked matrix can be explained by the ionic size of the crosslinker cations. The size of aluminum $(0.50 \AA)$ was smaller than the size of the iron $(0.64$ $\AA)$ cations. Iron ions were expected to fill larger space between the alginate chains producing a loose arrange- ment in the matrix leading to high release. Musa and coworkers [29] have studied the parameters involved in the preparation and release of metoclopramide hydrochloride and cisapride in calcium, barium, aluminum crosslinked matrices of alginate and reported that the crosslinker type was shown to have a pronounce influence on the drug release. In addition aluminum ion constitute complex with 5-FU causes low drug release. In the rest of the study due to the high release of 5-FU from Fe-Alg beads we have continued with $\mathrm{Fe}^{3+}$ as the crosslinker ion [32].

Figure 5 shows the effect of crosslinker concentration on the 5-FU release. It was seen from the figure that the cumulative release of 5-FU beads increased as the crosslinker concentration decreased from 0.2 to $0.05 \mathrm{M}$. Similar results were also observed in the literature [20, $30]$. In the rest of the study crosslinker concentration was selected as $0.05 \mathrm{M}$ due to the high release at this concentration.

\subsection{Effect of Exposure Time to Crosslinker on the 5-FU Release}

One of the ways of changing drug release from the beads

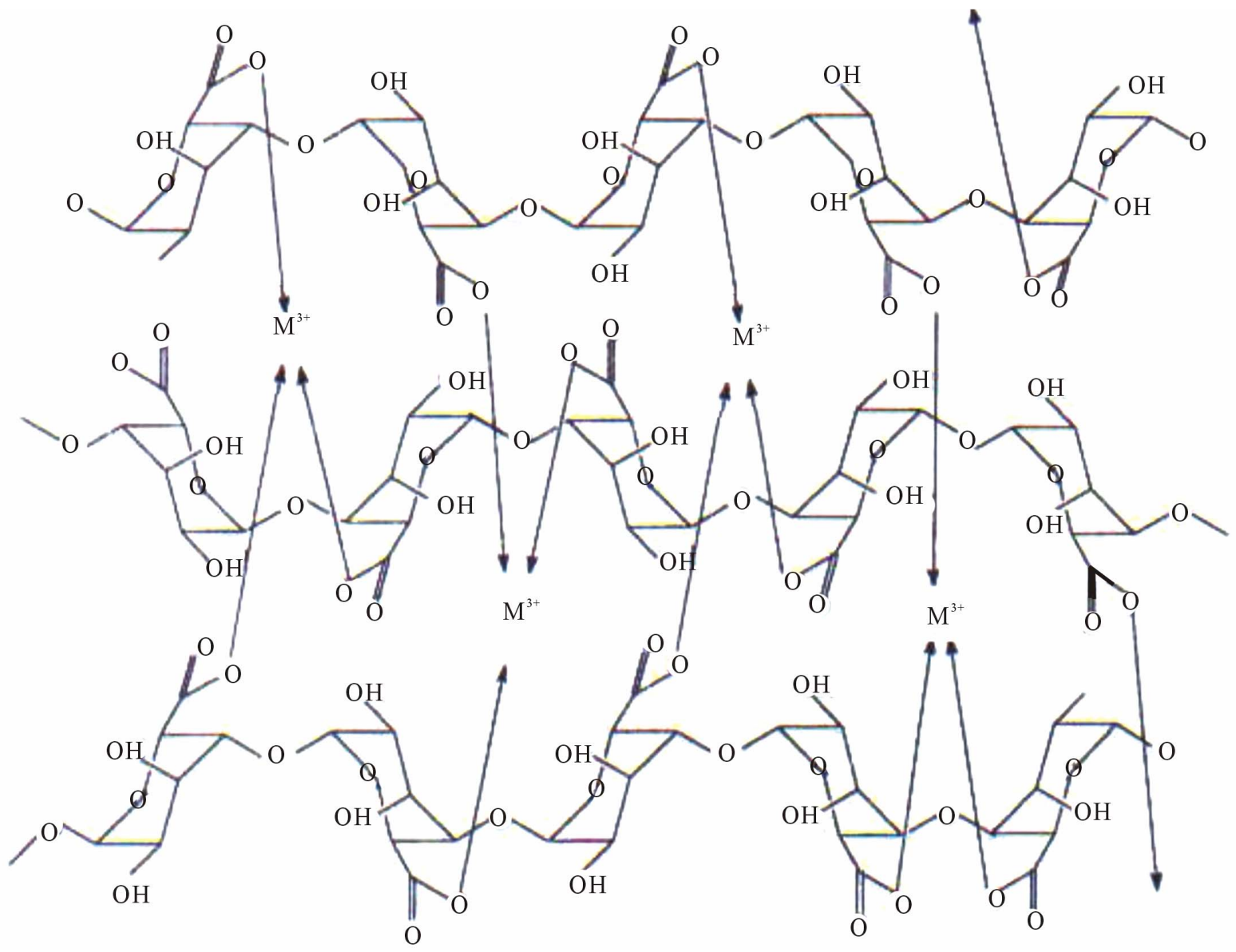

Scheme 2. Scheme for the crosslinking of NaAlg with $\left[\mathrm{M}^{3+}: \mathrm{Fe}^{3+}, \mathrm{Al}^{3+}\right.$ cations]. 
is to change the crosslinking density of the matrix by employing various time of exposure to crosslinking agent. The effect of the exposure time to $\mathrm{FeCl}_{3}$ on the release rate of 5-FU has been investigated by varying the time of exposure to $\mathrm{FeCl}_{3}$ as 5 - 15 min. The results were given in Figure 6, which clearly indicated that increasing exposure time to $\mathrm{FeCl}_{3}$ decreased the cumulative release of 5-FU. Similar results were given in the literature [4, $11,12,14]$. Although the maximum 5-FU release from the Fe-Alg beads was obtained with the exposure time of 5 min., since these beads did not stand to $\mathrm{pH}$ value of 7.4. We have continued in the rest of the study with exposure time of $10 \mathrm{~min}$.

\subsection{Effect of Drug/Polymer Ratio on the 5-FU Release}

Effect of 5-FU/NaAlg ratio on 5-FU release from Fe-Alg beads was shown in Figure 7. The figure showed that a decrease in the 5-FU/polymer ratio from $1 / 1$ to $1 / 8$ causes an increase in the release of 5 -FU from the beads.
The highest cumulative 5-FU release obtained at the end of $6 \mathrm{hr}$ is $90 \%$ for the $1 / 8 \mathrm{drug} /$ polymer ratio. As $5-\mathrm{FU}$ content of the bead decreases, a loose structure in the polymeric bead forms and this loose structure causes the liquid to easily penetrate into the bead and eases the diffusion of the 5-FU. As the drug/polymer ratio decreased from $1 / 1$ to $1 / 8$ particle size of the beads also decreased (Table 1). Release from smaller size bead is faster than those from the large size bead due to smaller diffusional path length for the drug and the larger surface area of contact of small particle with the dissolution media [33, 34].

\subsection{Characterization of the Beads}

FTIR spectra of 5-FU, 5-FU/NaAlg $(1 / 8 \mathrm{w} / \mathrm{w})$ beads crosslinked with $\mathrm{Fe}^{3+}$ and $\mathrm{NaAlg}$ were shown in Figure 1. A broad band between the 3000 and $3500 \mathrm{~cm}^{-1}$, is attributed to- $\mathrm{NH}$ stretching vibrations in the spectrum of 5 -FU. This band was seen approximately at $3500 \mathrm{~cm}^{-1}$ in the spectrum of drug loaded NaAlg, because the over-

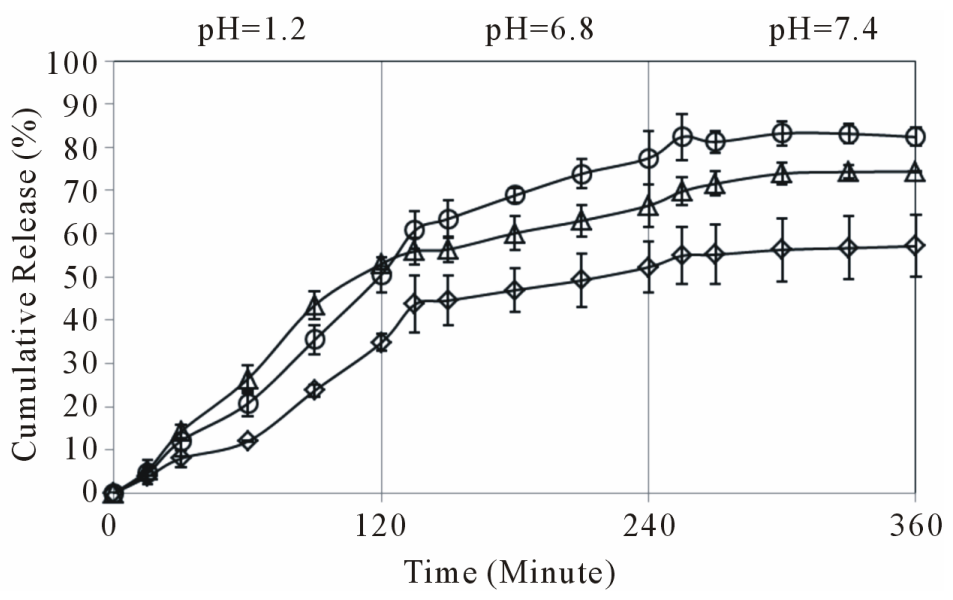

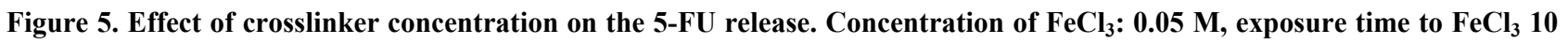
min. drug/polymer; $1 / 8(\diamond: 0.2 \mathrm{M}, \Delta: 0.1 \mathrm{M}, \circ: 0.05 \mathrm{M})$.

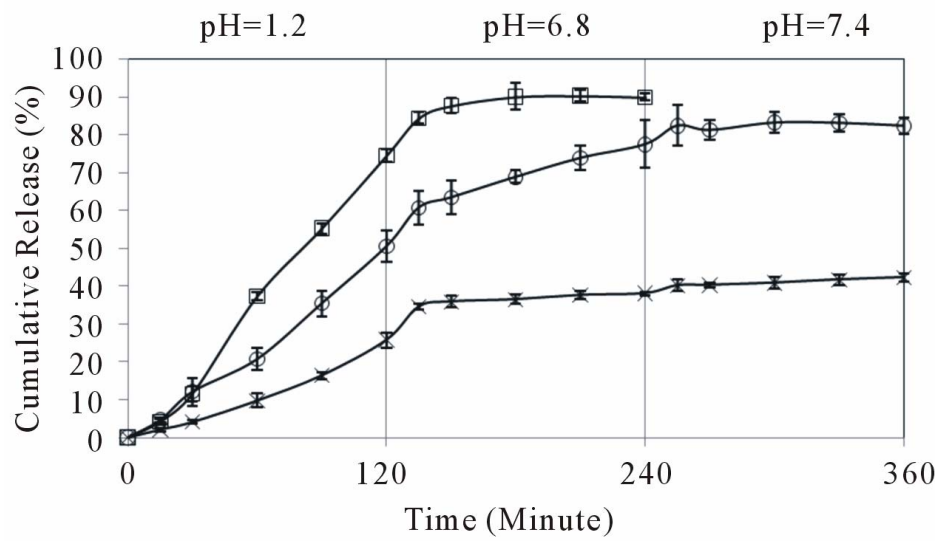

Figure 6. Effect of exposure time to crosslinker on the 5-FU release. Concentration of $\mathrm{FeCl}_{3}: 0.05 \mathrm{M}$, drug/polymer: 1/8. ( $\square$ : 5 min., $\bigcirc: 10$ min., $x: 15$ min). 


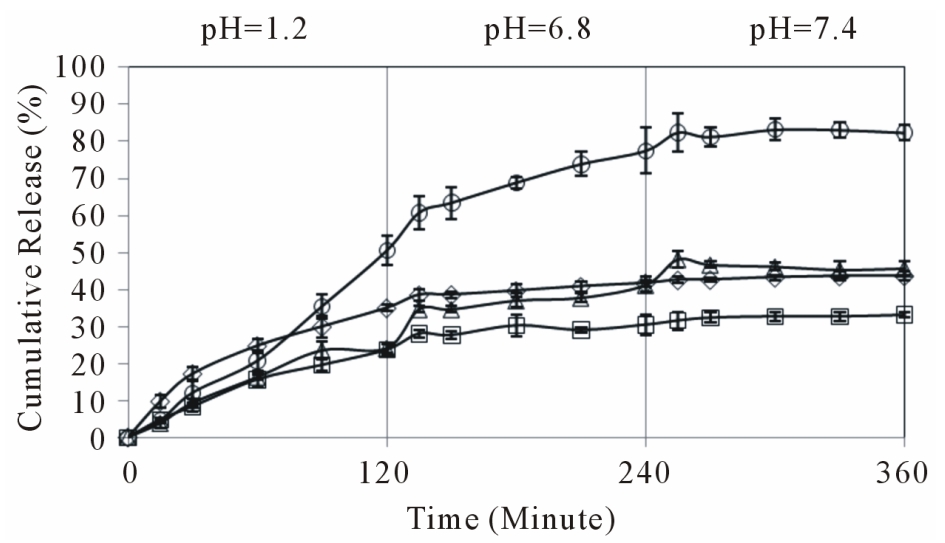

Figure 7. Effect of drug/polymer ratio on 5-FU release. Concentration of $\mathrm{FeCl}_{3}: \mathbf{0 . 0 5} \mathrm{M}$, exposure time to $\mathrm{FeCl}_{3} 10 \mathrm{~min}$ (drug/polymer ratio; 1/8 (०), 1/4 ( $\Delta), 1 / 2(\diamond), 1 / 1(\square))$.

overlapping of -OH band of NaAlg with -NH band of 5-fluorouracil. In the spectrum of $\mathrm{NaAlg}$, drug loaded $\mathrm{NaAlg}$ and 5-FU appeared band of carbonyl stretching $(\mathrm{C}=\mathrm{O})$ at $1650 \mathrm{~cm}^{-1}, 1625 \mathrm{~cm}^{-1}$ and $1638 \mathrm{~cm}^{-1}$, respecttively. C-H group stretching band of NaAlg and drug loaded NaAlg appeared were seen at $2930 \mathrm{~cm}^{-1} 2925$ $\mathrm{cm}^{-1}$, respectively. The peak at $1275 \mathrm{~cm}^{-1}$ was belong to C-F stretching band in the spectrum of 5-FU. This peak was seen at $1280 \mathrm{~cm}^{-1}$ in the spectrum of drug loaded $\mathrm{NaAlg}$ which can be taken as the evidence of encapsulation.

DSC trackings of pure 5-FU, NaAlg, NaAlg beads crosslinked with $\mathrm{FeCl}_{3}, 5$-FU loaded beads crosslinked with $\mathrm{FeCl}_{3}$ were displayed in Figure 2 melting peak of 5 -FU was observed at $282^{\circ} \mathrm{C}$. However no characteristic peak of 5-FU was observed in DSC curves of the 5-FU loaded beads suggesting that drug is molecularly dispersed in the polymer matrix.

Shape of dried empty NaAlg and 5-FU loaded NaAlg beads were shown in Figure 3. As it was reflected from the figure that, both empty and 5-FU loaded beads almost maintain spherical form at empty and loaded conditions.

The results of bead diameter, entrapment efficiency (\%) and bead yield (\%) were shown in Table 1. As can be seen from the table the beads formed have particle sizes ranging from 0.55 to $1.25 \mathrm{~mm}$ in diameter. The size of the beads changed with drug/polymer (w/w) ratio, crosslinker type and crosslinker concentration. Entrapment efficiency percentage increased with the increase in crosslinker concentration whereas decreased with the exposure time to crosslinker. Similar results were observed in the literature. Şanlı and coworkers [21] prepared poly(vinyl alcohol)/sodium alginate and poly(vinyl alcohol)-grafted-poly (acrylamide)/sodium alginate blend beads for the delivery of diclofenac sodium and reported that with increasing exposure time to crosslinking agent (2.5 - $5 \mathrm{~min}$.) the entrapment efficiency decreased.

\subsection{Analysis of Kinetic Results}

Solvent sorption by a bead depends mechanistically on the diffusion of water molecules into the gel matrix and subsequent relaxation of macromolecular chains of the bead [35]. The release data of all the systems were further substantiated by fitting the fraction release data $M_{t} / M_{\infty}$ to an empirical equation proposed by Peppas [36].

$$
\mathrm{kt}^{\mathrm{n}}=\frac{\mathrm{M}_{\mathrm{t}}}{\mathrm{M}_{\infty}}
$$

where $\mathrm{M}_{\mathrm{t}}$ is the amount of 5-FU released at time $t$ and $\mathrm{M}_{\infty}$ is the drug released at equilibrium time; $\mathrm{k}$, a constant characteristic of the drug-polymer system; and n, the diffusional exponent which suggests the nature of the release mechanism. Fickian release is defined by initial $\mathrm{t}^{1 / 2}$ time dependence of the fractional release for slabs, cylinders and spheres. Analogously Case-II transport is defined by an initial linear time dependence of the fractional release for all geometries [37]. A value of $n ; 0.5$ indicates the Fickian transport (mechanism), while $n ; 1$ is of Case II or non-Fickian transport (swelling controlled) [38]. The intermediary values ranging between 0.5 and 1.0 are indicative of the anomalous transport. The least squares estimations of the fractional release data along with the estimated correlation coefficient values, $r$, are presented in Table 3. From these data, the $\mathrm{n}$ value ranged between $0.4486-1.1506$, indicating 5 -FU release from the Fe-Alg beads deviates from the Fickian transport.

The values of diffusion coefficients, D, for the transport of aqueous drug solution from the beads were calculated using the sorption and desorption results as in Equation (7).

$$
\mathrm{D}=\left(\frac{\mathrm{r} \theta}{6 \mathrm{M}_{\infty}}\right)^{2} \pi
$$

where $\theta$ is the slope of the linear portion of the plot of 
Table 3. The results of $k$, $n$ and $r$ calculated from Equation (6).

\begin{tabular}{|c|c|c|c|c|c|}
\hline Formulation Code & $\mathrm{k}\left(\min ^{-\mathrm{n}}\right)$ & $\mathrm{n}$ & $\mathrm{r}$ & $\mathrm{D}\left(\mathrm{cm}^{2} / \mathrm{s}\right) \times 10^{-13}$ & Diffusion Mechanism \\
\hline A1 & 0.0040 & 0.7832 & 0.965 & 50.7 & Anomalous Transport \\
\hline A2 & 0.0039 & 0.8926 & 0.976 & 8.72 & Anomalous Transport \\
\hline A3 & 0.0067 & 0.8659 & 0.981 & 55.1 & Anomalous Transport \\
\hline A4 & 0.0025 & 1.1506 & 0.972 & 31.9 & Case II \\
\hline A5 & 0.0017 & 0.9911 & 0.969 & 15.2 & Anomalous Transport \\
\hline A6 & 0.0065 & 0.7624 & 0.978 & 13.3 & Anomalous Transport \\
\hline A7 & 0.0119 & 0.5979 & 0.970 & 0.0078 & Anomalous Transport \\
\hline A8 & 0.0363 & 0.4486 & 0.966 & 8.27 & Anomalous Transport \\
\hline
\end{tabular}

$\mathrm{M}_{\mathrm{t}} / \mathrm{M}_{\infty} \mathrm{vs} \mathrm{t} \mathrm{t}^{1 / 2}$, and $\mathrm{r}$ is the radius of the beads; $\mathrm{M}_{\infty}$ is equilibrium sorption. To calculate $\mathrm{D}$ from desorption experiments, $\theta$ was computed from the initial linear portion of the desorption plot, i.e. $\ln \left(1-\mathrm{M}_{\mathrm{t}} / \mathrm{M}_{\infty}\right)$ vs. time, t. The calculated values of $\mathrm{D}$ from Equation (7) for sorption and desorption runs are also presented in Table 3. The D values for desorption were smaller than those observed for sorption, and these ranged from $0.0078 \times 10^{-13}$ to $55.1 \times 10^{-13} \mathrm{~cm}^{2} / \mathrm{s}[38]$.

\section{Conclusion}

Studies on the release of 5-FU from sodium alginate beads crosslinked with $\mathrm{Fe}(\mathrm{III}), \mathrm{Al}(\mathrm{III}), \mathrm{Zn}$ (II) and $\mathrm{Ca}$ (II) ions indicated that the crosslinking with Fe(III) lead to highest release of 5-FU from the beads. Release of 5-FU from $\mathrm{NaAlg}$ beads crosslinked with $\mathrm{FeCl}_{3}$ increased with the decrease in the drug content. It was also observed that release of 5-FU was much higher at high $\mathrm{pH}$ values compared to low $\mathrm{pH}$ values. Optimum conditions for 5-FU release were determined as crosslinker concentration of $0.05 \mathrm{M}$, exposure time to crosslinker of $10 \mathrm{~min}$ and drug/ polymer ratio of $1 / 8$. The highest 5 -FU release at these conditions was found to be $90 \%(\mathrm{w} / \mathrm{w})$.

\section{Acknowledgements}

The authors are grateful to the Gazi University Scientific Research Foundation for support of this study.

\section{REFERENCES}

[1] R. S. Sastre, R. Olmo, C. Teijon, E. Muniz, J. M. Teijon and M. D. Blanco, "5-Fluorouracil Plasma Levels and Biodegradation of Subcutaneously Injected Drug-Loaded Microspheres Prepared by Spray-Drying Poly(D,L-lactide) and Poly(D,L-lactide-co-glycolide) Polymers," International Journal of Pharmaceutics, Vol. 338, No. 1-2, 2007, pp. 180-190. doi:10.1016/j.ijpharm.2007.02.001

[2] V. R. Babu, M. Sairam, K. M. Hosamani and T. M. Ami- nabhavi, "Development of 5-Fluorouracil Loaded Poly (Acrylamide-co-methylmethacrylate) Novel Core-Shell Microsheres: In Vitro Release Studies," International Journal of Pharmaceutics, Vol. 325, No. 1-2, 2006, pp. 55-62. doi:10.1016/j.ijpharm.2006.06.020

[3] Q. Wang, Y. Du and L. Fan, "Properties of Chitosan/ Poly(vinyl alcohol) Films for Drug-Controlled Release," Journal of Applied Polymer Science, Vol. 96, No. 3, 2005, pp. 808-813. doi:10.1002/app.21518

[4] E. Fournier, C. Passirani, A. Vonarbourg, L. Lemaire, N. Colin, S. Sagodira, P. Menei and J. P. Benoit, "Therapeutic Efficacy Study of Novel 5-FU-Loaded PMM 2.1.2Based Microspheres on C6 Glioma," International Journal of Pharmaceutics, Vol. 268, No. 1-2, 2003, pp. 31-35. doi:10.1016/j.ijpharm.2003.08.014

[5] J. M. Kauffman, S. K. Sengupta and W. O. Foye, "Cancer Chemoteraphy," 3rd Edition, Varghese Publishing House, Bombay, 1989.

[6] P. Menei, E. Jadaud, N. Faisant, M. Boisdron-Celle, S. Michalak, D. Fournier, M. Delhaye and J. P. Benoit, "Stereotaxic Implantation of 5-Fluorouracil-Releasing Microspheres in Malignant Glioma," Cancer, Vol. 100, No. 2, 2004, pp. 405-410. doi:10.1002/cncr.11922

[7] K. Çiftçi, H. S. Kaş, A. A. Hıncal, T. M. Ercan, O. Güven and Ş. Raucan, "In Vitro and In Vivo Evaluation of PLAGA (50/50) Microspheres Containing 5-Fluorouracil Prepared by a Solvent Evaporation Method," International Journal of Pharmaceutics, Vol. 131, No. 1, 1996, pp. 73-82. doi:10.1016/0378-5173(95)04369-1

[8] M. Hussain, G. Beale, M. Hughes, S. Akhtar, "Co-Delivery of an Antisense Oligonucleotide and 5-Fluorouracil Using Sustained Release Poly(Lactide-co-glycolide) Microsphere Formulations for Potential Combination Therapy in Cancer," International Journal of Pharmaceutics, Vol. 234, No. 1-2, 2002, pp. 129-138. doi:10.1016/S0378-5173(01)00950-4

[9] C. Zinutti, F. Kedzierewicz, M. Hoffman, J. P. Benoit, P. Maincent, "Influence of the Casting Solvent on the Physico-Chemical Properties of 5-Fluorouracil Loaded Microspheres," International Journal of Pharmaceutics, Vol. 133, No. 1-2, 1996, pp. 97-105. doi:10.1016/0378-5173(95)04423-X 
[10] K. B. Gudasi, R. S. Vadavi, N. B. Shelke, M. Sairam, T. M. Aminabhavi, "Synthesis and Characterization of Novel Polyorganophosphazanes Substituted with 4-Methoxybenzylamine and 4-Methoxyphenethylamine for In Vitro Release of Indomethacin and 5-Fluorouracil," Reactive and Functional Polymers, Vol. 66, No. 10, 2006, pp. 1149-1157. doi:10.1016/j.reactfunctpolym.2006.02.007

[11] C. Zhang, Y. Cheng, G. Qu, X. Wu, Y. Ding, Z. Cheng, L. $\mathrm{Yu}$ and Q. Ping, "Preparation and Characterization of Galactosylated Chitosan Coated BSA Microspheres Containing 5-Fluorouracil," Carbohydrate Polymer, Vol. 72, No. 3, 2008, pp. 390-397. doi:10.1016/j.carbpol.2007.09.004

[12] M. G. Dodova, S. Calis, M. S. Crcarevskaa, N. Geskovski, V. Petrovskaa and K. Goracinova, "Wheat Germ Agglutinin-Conjugated Chitosan-Ca-Alginate Microparticles for Local Colon Delivery of 5-FU: Development and In Vitro Characterization," International Journal of Pharmaceutics, Vol. 381, No. 2, 2009, pp. 166-175. doi:10.1016/j.ijpharm.2009.06.037

[13] C.-Y. Yu, X.-C. Zhang, F.-Z. Zhou, X.-Z. Zhang, S.-X. Cheng and R.-X. Zhuo, "Sustained Release of Antineoplastic Drugs from Chitosan-Reinforced Alginate Microparticle Drug Delivery Systems," International Journal of Pharma-ceutics, Vol. 357, No. 1-2, 2008, pp. 15-21. doi:10.1016/j.ijpharm.2008.01.030

[14] R. Jeyanthi and K. P. Rao, "Release Characteristics of Bleomycin Mitomycin C and 5-Fluorouracil from Gelatin Microspheres," International Journal of Pharmaceutics, Vol. 55, No. 1, 1989, pp. 31-37. doi:10.1016/0378-5173(89)90273-1

[15] L. Huang, W. Sui, Y. Wang and Q. Jiao, "Preparation of Chitosan/Chondroitin Sulfate Complex Microcapsules and Application in Controlled Release of 5-Fluorouracil," Carbohydrate Polymer, Vol. 80, No. 1, 2010, pp. 168-173. doi:10.1016/j.carbpol.2009.11.007

[16] A. Gupte and K. Ciftci, "Formulation and Characterization of Paclitaxel, 5-Fu and Paclitaxel + 5-Fu Microspheres," International Journal of Pharmaceutics, Vol. 276, No. 1, 2004, pp. 93-106.

[17] B. Arıca, S. Çalış, H. S. Kaş, M. F. Sargon and A. A. Hincal, "5-Fluorouracil Encapsulated Alginate Beads for the Treatment of Breast Cancer," International Journal of Pharmaceutics, Vol. 242, No. 1-2, 2002, pp. 267-269. doi:10.1016/S0378-5173(02)00172-2

[18] M. G. Dodova, S. Calis, M. S. Crcarevskaa, N. Geskovski, V. Petrovskaa and K. Goracinova, "Wheat Germ Agglutinin-Conjugated Chitosan-Ca-Alginate Microparticles for Local Colon Delivery of 5-FU: Development and In Vitro characterization," International Journal of Pharmaceutics, Vol. 381, No. 2, 2009, pp. 166-175. doi:10.1016/j.ijpharm.2009.06.037

[19] A. B. Pepperman and J. C. W. Kuan, "Controlled Release Formulations of Alachlor Based on Calcium Alginate," Journal of Controlled Release, Vol. 34, No. 1, 1995, pp. 17-23. doi:10.1016/0168-3659(94)00111-7

[20] S. G. Kumbar and T. M. Aminabhavi, "Preparation and Characterization of Interpenetrating Network Beads of Poly(Vinyl Alcohol)-Grafted-Poly(Acrylamide) with Sodi- um Alginate and Their Controlled Release Characteristics for Cypermethrin Pesticide," Journal of Applied Polymer Science, Vol. 84, No. 3, 2002, pp. 552-560. doi:10.1002/app.10306

[21] O. Şanlı, N. Ay and N. Işıklan, "Release Characteristics of Diclofenac Sodium from Poly(Vinyl Alcohol)/Sodium Alginate and Poly(Vinyl Alcohol)-Grafted Poly(Acrylamide)/Sodium Alginate Blend Beads," European Journal of Pharmaceutics and Biopharmaceutics, Vol. 65, No. 2, 2007, pp. 204-214. doi:10.1016/j.ejpb.2006.08.004

[22] V. Pillay, C. M. Dangor, T. Govender, K. R. Moopanar and N. Hurbans, "Ionotropic Gelation: Encapsulation of Indomethacin in Calcium Alginate Gel Disks," Journal of Microencapsulation, Vol. 15, No. 2, 1998, pp. 215-226. doi:10.3109/02652049809006851

[23] V. R. Babu, S. Malladi, K. M. Hasamani, T. M. Aminabhavi, "Preparation of Sodium Alginate-Methylcellulose Blend Microspheres for Controlled Release of Nifedipine," Carbohydrate Polymer, Vol. 69, No. 2, 2007, pp. 241-250. doi:10.1016/j.carbpol.2006.09.027

[24] A. R. Kulkarni, K. S. Soppimath, T. M. Aminabhavi, W. E. Rudzinski, "In Vitro Release Kinetics of CefadroxilLoaded Sodium Alginate Interpenetrating Network Beads," European Journal of Pharmaceutics and Biopharmaceutics, Vol. 51, No. 2, 2001, pp. 127-133. doi:10.1016/S0939-6411(00)00150-8

[25] A. Nokhodchi and A. Tailor, "In Situ Cross-Linking of Sodium Alginate with Calcium and Aluminum Ions to Sustain the Release of Theophyline from Polymeric Matrices," II. Farmaco, Vol. 59, No. 12, 2004, pp. 999-1004. doi:10.1016/j.farmac.2004.08.006

[26] M. O. Taha, W. Nasser, A. Ardakani and H. S. AlKhatib, "Sodium Laurly Sulfate Impedesdrug Release from Zinc-Crosslinked Alginate Beads: Swithching from Enteric Coating Release into Biphasic Profiles," International Journal of Pharmaceutics, Vol. 350, No. 1-2, 2008, pp. 291-300. doi:10.1016/j.ijpharm.2007.09.010

[27] B. Arıca, S. Çalış, H. S. Kaş, M. F. Sargon and A. A. Hincal, "5-Fluorouracil Encapsulated Alginate Beads for the Treatment of Breast Cancer," International Journal of Pharmaceutics, Vol. 242, No. 1-2, 2002, pp. 267-269. doi:10.1016/S0378-5173(02)00172-2

[28] S. Nagaich, A. J. Khopade and N. K. Jain, "Lipid Grafts Egg-Box Complex: A New Supramolecular Biovector for 5-Fluorouracil Delivery," Pharmaceutica Acta Helvetiae, Vol. 73, No. 5, 1999, pp. 227-236. doi:10.1016/S0031-6865(98)00027-2

[29] S. Al-Musa, D. A. Fara and A. A. Badwan, "Evaluation of Parameters Involved in Preparation and Release of Drug Loaded in Crosslinked Matrices of Alginate," Journal of Controlled Release, Vol. 57, No. 3, 1999, pp. 223-232. doi:10.1016/S0168-3659(98)00096-0

[30] M. S. Kim, S. J. Park, B. K. Gu and C. H. Kim, "Ionically crosslinked alginate-carboxymethyl cellulose beads for the delivery of protein therapeutics," Applied Surface Science, 2012, in Press.

[31] G. Li, Y. Du, Y. Tao, H. Deng, X. Luo and J. Yang, "Iron (II) Cross-Linked Chitin-Based Gel Beads: Preparation, Magnetic Property and Adsorption of Methyl Orange," 
Carbohydrate Polymers, Vol. 82, No. 3, 2010, pp. 706713. doi:10.1016/j.carbpol.2010.05.040

[32] O. Şanlı and N. Işıklan, "Controlled Release Formulations of Carbaryl Based on Copper Alginate, Barium Alginate and Alginic Acid Beads," Journal of Applied Polymer Science, Vol. 102, No. 5, 2006, pp. 4245-4253. doi:10.1002/app.24882

[33] E. Akalin, S. Akyuz and T. Akyuz, "Adsorption and Interaction of 5-Fluorouracil with Montromorillonite and Sponite by FTIR Spectroscopy," Journal of Molecular Structure, Vol. 834-836, 2007, pp. 477-481. doi:10.1016/j.molstruc.2006.11.061

[34] I. M. El-Sherbiny, R. J. Lins, E. M. Abdel-Bary and D. R. K. Harding, "Preparation, Characterization, Swelling and In Vitro Drug Release Behaviour of Poly[ $\mathrm{N}$-acryloylglycine-chitosan] Interpolymeric $\mathrm{pH}$ and Thermally-Responsive Hydrogels," European Polymer Journal, Vol. 41, No. 11,2005 , pp. 2584-2591. doi:10.1016/j.eurpolymj.2005.05.035
[35] A. K. Bajpai and M. Sharma, "Preparation and Characterization of Binary Grafted Polymeric Blends of Polyvinyl Alcohol and Gelatin and Evaluation of Their Water Uptake Potential Part A," Pure and Applied Chemistry, Vol. 42, No. 5, 2005, pp. 663-682.

[36] N. A. Peppas, "Analysis of Fickian and Non-Fickian Drug Release from Polymers," Pharmaceutica Acta Helvetiae, Vol. 60, No. 4, 1985, pp. 110-111.

[37] P. L. Ritger and N. A. Peppas, "A Simple Equation for Description of Solute Release II. Fickian and Anomalous Release from Swellable Devices," Journal of Controlled Release, Vol. 5, No. 1, 1987, pp. 37-42. doi:10.1016/0168-3659(87)90035-6

[38] V. R. Babu, K. S. V. Krishna Rao, M. Sairam, B. Vijaya Kumar Naidu, K. M. Hosamani and T. M. Aminabhavi, "pH Sensitive Interpenetrating Network Microgels of Sodium Alginate-Acrylic Acid for the Controlled Release of Ibuprofen," Journal of Applied Polymer Science, Vol. 99, No. 5, 2006, pp. 2671-2678. doi:10.1002/app.22760 